\title{
Intraepithelial matrix metalloproteinase-9 in invasive breast carcinoma, normal tissue adjacent to tumor, and normal mammoplasty specimens: a comparative study considering relationship between matrix metalloproteinase- 9 and some clinicopathologic prognostic factors of breast carcinoma
}

Fereshteh Mohammadizadeh

Isfahan University of Medical Sciences

Mahsa Bagherian Dehkordi ( $\triangle$ mbagherian8976@gmail.com )

Isfahan University of Medical Sciences https://orcid.org/0000-0002-5871-9558

Research article

Keywords: matrix metalloproteinase-9, breast cancer, immunohistochemistry, prognostic factors

Posted Date: March 11th, 2020

DOl: https://doi.org/10.21203/rs.3.rs-16942/v1

License: (c) (1) This work is licensed under a Creative Commons Attribution 4.0 International License.

Read Full License 


\section{Abstract}

Background- Matrix metalloproteinase-9 (MMP-9), an enzyme with major role in remodeling of extracellular matrix, has been the focus of attention in some previous studies in the field of breast cancer. We conducted a comparative study to investigate the frequency of this marker in tissue specimens of invasive breast carcinoma, tumor control, and normal control. The relationship between matrix metalloproteinase-9 and some clinicopathologic factors of breast carcinoma has also been evaluated.

Methods- Formalin-fixed and paraffin-embedded tissue specimens from three groups including 40 invasive breast carcinoma (tumor group) and their adjacent normal tissue (tumor control), as well as 40 normal mammoplasty specimens (normal control) were studied. The samples were from the pathology archive of Alzahra Hospital, Isfahan, Iran, from 2016 to 2018. The status of intraepithelial MMP-9 was studied and compared in these three groups using immunohistochemistry. The relationship between intraepithelial MMP-9 and some clinicopathologic prognostic factors was also evaluated in tumor group.

Results - The extent of intraepithelial MMP-9 immunostaining in all positive specimens was $100 \%$. The results of intraepithelial MMP-9 staining intensity was as follow: $12.5 \%$ strong, $27.5 \%$ moderate, $27.5 \%$ mild, and $32.5 \%$ negative in tumor group; $17.5 \%$ strong, $22.5 \%$ moderate, $32.5 \%$ mild, and $27.5 \%$ negative in tumor control group; and $10 \%$ strong, $40 \%$ moderate, $27.5 \%$ mild, and $22.5 \%$ negative in normal control group. Intraepithelial MMP-9 immunostaining intensity showed significant difference between tumor and tumor control groups $(P<0.001)$. Intraepithelial MMP-9 immunostaining intensity showed no significant difference between tumor and normal control groups, and between tumor control and normal control groups $(P>0.05)$.

\section{Background:}

Breast carcinoma is the most prevalent non-skin carcinoma in women and the second cause of cancer related mortalities after lung cancer. There is a chance of 1:8 for breast cancer in a woman aged around 90 years. In a study performed in 2012 in the United States, there was 40000 deaths among 226000 women with invasive breast carcinoma. This data points to the tragic issue of social and economic burden of breast cancer in societies (1-3).

Cancer registry reports indicate breast cancer as the most prevalent malignant tumor among Iranian women (4). There are definitive risk factors for breast cancer including early menarche, late menopause, nulliparity, and positive familial history. However, several molecules have been the focus of attention as probable determinant factors of breast cancer behavior and outcome in recent years $(5,6)$.

Matrix metalloproteinases (MMPs) are a huge family of extracellular enzymes dependent to zinc and calcium. These enzymes are categorized based on their function and structures into matrilysin, gelatinases, stromelysin, and collagenases (7). 
MMP-9 is one of the most important gelatinases which is highly effective in tumoral invasion and destruction of type IV collagen and other components of extracellular matrix $(8,9)$.

There is low expression of MMPs in normal tissues. Increased activity and expression of these enzymes causes tissue destruction. This situation occurs in inflammatory diseases and tumors. As a result, MMPs have been considered as a marker for tissue destruction (10).

Early diagnosis of breast cancer and its micro-metastases are pivotal factors in cancer treatment. Some studies have found relationship between MMP-9 expression and prevalence of metastasis in breast carcinoma $(11,12)$. Stromal MMP-9 expression has been shown as a predicting factor for hormonal response and survival in patients with breast cancer (13). The relationship between MMP-9 expression and lymph node status has also been reported in patients with breast cancer (14). However, the results of previous studies on the issue of MMP-9 expression in breast cancer and its impact on tumor prognosis has not been yet conclusive. The objective of this study has been to assess the frequency of intracellular expression of MMP-9 in invasive breast carcinoma and normal breast tissue, and to investigate the relationship between intracellular expression of this marker in breast carcinoma and some well-known clinicopathological prognostic variables of this cancer.

\section{Methods:}

This cross-sectional study was performed on formalin-fixed and paraffin-embedded tissue blocks from 40 invasive breast carcinomas (tumor group) and normal tissue adjacent to carcinoma (tumor control group), as well as 40 normal breast tissue specimens from mammoplastic surgery (normal control group). The specimens were obtained from pathology archive of Alzahra Hospital, Isfahan, Iran, from 2016 to 2018 . The study was approved by ethical committee of Isfahan University of Medical Sciences, Isfahan, Iran (Ethical code: IR.MUI.MED.REC.1398.055). Inclusion criteria were breast lumpectomy or mastectomy specimens with documented diagnosis of invasive breast carcinoma having normal tissue adjacent to carcinoma and dissected axillary lymph nodes. Concerning normal control group, only mammoplasty specimens having normal breast tissue without any kind of breast pathology were included in the study. Exclusion criteria were those carcinoma specimens without adjacent normal breast tissue and/or lacking dissected axillary lymph nodes. Concerning normal control group, mammoplasty specimens with any kind of breast pathology were excluded from the study.

We used immunohistochemistry to stain all 120 specimens with MMP-9 antibody (Rabbit Polyclonal Antibody, Diagnostic BioSystems, Canada). Five micron sections were prepared from tissue blocks and underwent immunohistochemical staining according to the following steps:

48 hours incubation in oven at $37^{\circ} \mathrm{C}$, dewaxation by $100 \%$ xylol, rehydration by decreasing concentrations of ethanol $(100 \%, 85 \%$, and $75 \%)$, rinsing in $10 \%$ phosphate-buffered saline (PBS) solution, 30 minutes incubation in 10\% $\mathrm{H} 2 \mathrm{O} 2$ and methanol to inhibit endogenous peroxidase activity, rinsing in 10\% PBS solution, 14 minutes incubation in citrate-buffered solution (PH = 6.1) in microwave, rinsing in $10 \%$ PBS solution, adding blocking serum for 30 minutes to block endogenous non-specific 
bindings, drying, adding primary monoclonal antibody, 30 minutes incubation at room temperature, rinsing in 10\% PBS solution, adding broad-spectrum secondary antibody for 30 minutes, adding horseradish peroxidase-streptavidin and diaminobenzidine (DAB) for 30 minutes and 10 minutes, respectively, rinsing in $10 \%$ PBS solution, dehydration by increasing concentrations of ethanol $(75 \%, 85 \%$, and $100 \%$ ), and counterstaining with hematoxylin.

The intensity and extent of cytoplasmic MMP-9 immunoreactivity + were then examined in epithelial cells of breast carcinoma and normal breast tissue. Epithelial cells, fibroblasts, and extracellular matrix all may show immunoreactivity with MMP-9 antibody $(13,14)$. However, only MMP-9 expression in epithelial cells has been considered in this study. Scores of staining intensity were defined as follow (13-16):

\section{Score 0: Negative}

\section{Score 1: Mild}

\section{Score 2: Moderate}

\section{Score 3: strong}

The percentage of stained epithelial cells irrespective of the intensity of staining was evaluated to determine and classify staining extent as follow (13-16):

\section{Score 0: 0 to $10 \%$}

\section{Score 1: 11 to $25 \%$}

\section{Score 2: 26 to $50 \%$}

\section{Score 3: 51 to $75 \%$}

\section{Score 4: 76 to $100 \%$}

The intensity and extent of cytoplasmic staining of MMP-9 in epithelial cells was then compared between the three groups. In tumor group, the relationship between intraepithelial MMP-9 expression and some prognostic factors including age, tumor size, tumor grade, and lymph node status was also studied. Data concerning age, tumor size (greatest tumor diameter), tumor grade, and lymph node status were all achieved from pathology archive of the hospital. SPSS software, version 24, was used for data analysis. Data were shown as frequency, mean, and standard deviation (SD). To determine the relationship between MMP-9 expression and prognostic variables in tumor group, Chi-Square and one-way ANOVA were used. P-value less than 0.05 was considered as significant.

\section{Results:}


In this study, we evaluated 40 specimens of invasive breast carcinoma (tumor group) and normal tissue adjacent to these carcinoma specimens (tumor control group), as well as 40 normal control specimens from mammoplastic surgery (normal control group). The extent of intraepithelial MMP-9 immunostaining in all positive specimens was $100 \%$. The results of intraepithelial MMP-9 staining intensity was as follow: $12.5 \%$ strong, $27.5 \%$ moderate, $27.5 \%$ mild, and $32.5 \%$ negative in tumor group; $17.5 \%$ strong, $22.5 \%$ moderate, $32.5 \%$ mild, and $27.5 \%$ negative in tumor control group; and $10 \%$ strong, $40 \%$ moderate, $27.5 \%$ mild, and 22.5\% negative in normal control group (Table 1) (Fig. 1). Intraepithelial MMP-9 immunostaining intensity showed significant difference between tumor and tumor control groups $(\mathrm{P}<$ 0.001) (Table 2). Intraepithelial MMP-9 immunostaining intensity showed no significant difference between tumor and normal control groups, and between tumor control and normal control groups $(P>$ 0.05).

Table 1

Intraepithelial MMP-9 staining intensity in tumor, tumor control, and normal control groups

\begin{tabular}{|lllll|}
\hline MMP-9 staining & Tumor & Tumor control & Normal & Total \\
\hline Negative & $13(32.5 \%)$ & $11(27.5 \%)$ & $9(22.5 \%)$ & $33(27.5 \%)$ \\
\hline Mild & $11(27.5 \%)$ & $13(32.5 \%)$ & $11(27.5 \%)$ & $35(29.2 \%)$ \\
\hline Moderate & $11(27.5 \%)$ & $9(22.5 \%)$ & $16(40 \%)$ & $36(30 \%)$ \\
\hline Strong & $5(12.5 \%)$ & $7(17.5 \%)$ & $4(10 \%)$ & $16(13.3 \%)$ \\
\hline
\end{tabular}

Table 2

Comparison of intraepithelial MMP-9 staining intensity between tumor and tumor control groups

\begin{tabular}{|lllllll|}
\hline \multirow{5}{*}{ Tumor control } & & \multicolumn{2}{l}{ Tumor } & & \multicolumn{2}{c|}{ P-value } \\
\cline { 2 - 6 } & & Negative & Mild & Moderate & Strong & \\
\cline { 2 - 6 } & Negative & $11(84.6 \%)$ & 0 & 0 & 0 & $<0.001$ \\
\cline { 2 - 6 } & Mild & $2(15.4 \%)$ & $7(63.6 \%)$ & $3(27.3 \%)$ & $1(20 \%)$ & \\
\cline { 2 - 6 } & Moderate & 0 & $3(27.3 \%)$ & $5(45.5 \%)$ & $1(20 \%)$ & \\
\cline { 2 - 6 } & Strong & 0 & $1(9.1 \%)$ & $3(27.3 \%)$ & $3(60 \%)$ & \\
\hline
\end{tabular}

In tumor group, the means of age, tumor size, and involved lymph nodes were 44.15 years, $4.37 \mathrm{~cm}$, and 3.75 , respectively. $10 \%, 57.5 \%$, and $32.5 \%$ of tumors were grade I, grade II, and grade III, respectively. No significant relationship was seen between MMP-9 immunostaining intensity and age, tumor size, tumor grade, and lymph node status in tumor group $(P>0.05)$ (Table 3$)$. 
Table 3

Relationship between intraepithelial MMP-9 staining intensity and age, tumor grade, tumor size, and lymph node status in tumor group

\begin{tabular}{|c|c|c|c|c|c|c|c|}
\hline \multicolumn{2}{|c|}{ variable } & \multicolumn{4}{|c|}{ MMP-9 staining of tumor tissue } & \multirow{2}{*}{$\begin{array}{l}\text { Total }(n= \\
40)\end{array}$} & \multirow{2}{*}{$\begin{array}{l}\mathrm{P}- \\
\text { value }\end{array}$} \\
\hline & & $\begin{array}{l}\text { Negative }(n= \\
13)\end{array}$ & $\begin{array}{l}\text { Mild }(n= \\
11)\end{array}$ & $\begin{array}{l}\text { Moderate (n } \\
=11 \text { ) }\end{array}$ & $\begin{array}{l}\text { Strong ( } \\
=5)\end{array}$ & & \\
\hline Age & & $42.38 \pm 10.71$ & $\begin{array}{l}43.55 \pm \\
9.51\end{array}$ & $46.09 \pm 7.44$ & $\begin{array}{l}45.80 \pm \\
13.64\end{array}$ & $\begin{array}{l}44.15 \pm \\
9.71\end{array}$ & 0.80 \\
\hline \multirow[t]{3}{*}{ Grade } & I & $1(7.7 \%)$ & $1(9.1 \%)$ & $1(9.1 \%)$ & $4(10 \%)$ & $4(10 \%)$ & \multirow[t]{3}{*}{0.37} \\
\hline & ॥ & $7(53.8 \%)$ & $8(72.7 \%)$ & $4(36.4 \%)$ & $\begin{array}{l}23 \\
(57.5 \%)\end{array}$ & $\begin{array}{l}23 \\
(57.5 \%)\end{array}$ & \\
\hline & III & $5(38.5 \%)$ & $2(18.2 \%)$ & $6(54.5 \%)$ & $\begin{array}{l}13 \\
(32.5 \%)\end{array}$ & $\begin{array}{l}13 \\
(32.5 \%)\end{array}$ & \\
\hline \multicolumn{2}{|l|}{ Size } & $4.75 \pm 3.72$ & $\begin{array}{l}3.13 \pm \\
1.26\end{array}$ & $5.31 \pm 2.75$ & $\begin{array}{l}4.06 \pm \\
2.36\end{array}$ & $\begin{array}{l}4.37 \pm \\
2.81\end{array}$ & 0.31 \\
\hline \multicolumn{2}{|c|}{$\begin{array}{l}\text { Involved Lymph } \\
\text { node }\end{array}$} & $3.62 \pm 4.40$ & $\begin{array}{l}4.55 \pm \\
4.90\end{array}$ & $3.45 \pm 4.82$ & $\begin{array}{l}3.01 \pm \\
2.01\end{array}$ & $\begin{array}{l}3.75 \pm \\
4.33\end{array}$ & 0.90 \\
\hline
\end{tabular}

\section{Discussion}

In this study, intracellular MMP-9 staining intensity showed a significant difference between breast carcinoma and normal tissue adjacent to carcinoma. This finding suggests increased MMP-9 expression as an event in the pathway of transformation of normal breast epithelium to carcinoma cells. Concerning the association between MMP-9 expression and clinicopathological prognostic factors, we could not find any significant relationship between expression of this marker and age, tumor size, tumor grade, and lymph node status. This finding is different from most previous studies on this issue.

Matrix metalloproteinases, a family of key molecules in regulating microenvironment of tissues, have been studied as probable prognostic markers of breast cancer. Shen et al evaluated 27-

hydroxycholesterol in breast cancer and found this molecule to cause metastasis and more invasive behavior in breast carcinoma by increasing MMP-9 (18). Milovanovic et al indicated that tamoxifen performs its therapeutic effects on breast carcinoma by influencing MMP-2 (19). Furthermore, some studies have indicated that levels of MMP-9 in both serum and tissue of patients with breast cancer might be a determinant of tumor structure (20-24). Padala et al showed synergistic effects of MMP-1, MMP-3 and MMP-9 in breast carcinoma (25). Sun et al showed that higher levels of glucose might influence increased invasiveness of tumors by regulating Glut-1/ MMP-2/ MMP-9 axis (26). In another study by Lou et al, arctigenin was found to have therapeutic effects against cancer with the mechanism of reducing MMP-2/-9 expression in MDA- MB-231 cells (27). These studies emphasize on the hypothesis 
that MMP-9 might be an important factor in pathogenesis of breast carcinoma. Reggiani et al showed that MMP-9 promotes the protumorigenic effect of white adipose tissue progenitors on local and metastatic breast cancer (28). Wu et al evaluated 60 tissue samples of breast cancer and investigated MMP-9 and its mRNA in tumor tissue using immunohistochemistry and in situ hybridization. They also evaluated serum and tissue levels of MMP-9 and compared it with clinical and pathological characteristics of patients. Their results showed that serum levels of MMP-9 is highly increased in patients with breast cancer compared to normal population. This increase was also associated with lymph node metastasis, higher tumor grade, shorter relapse-free period, and reduced overall survival (29). Li et al found MMP-9 and MMP-2 markers to have high prognostic value in lymph node negative breast carcinoma (30). Mylona et al suggested the possible relationship between cytoplasmic MMP-9 and welldifferentiated breast carcinoma, while they found stromal MMP-9 to be associated with an aggressive phenotype of breast cancer (31). These findings are different from the results of our study. This discrepancy in results may be attributive to different study populations. However, more studies are needed before making any conclusive justification of this discrepancy.

\section{Conclusions:}

The results of this study suggest increased MMP-9 expression as an event in the pathway of transformation of normal breast epithelium to carcinoma cells. Concerning the association between MMP-9 expression and clinicopathological prognostic factors, we could not find any significant relationship between expression of this marker and age, tumor size, tumor grade, and lymph node status.

\section{Declarations}

\section{Abbreviations:}

MMP: matrix metalloproteinase

\section{Ethics approval and consent to participate:}

This study has been approved by ethical committee of Isfahan University of Medical Sciences, Isfahan, Iran (Ethical code: IR.MUI.MED.REC.1398.055).

\section{Consent for publication:}

Not applicable.

\section{Availability of data and material:}

All data and material are available.

\section{Competing interests:}


The authors have no competing interests regarding the subject studied in this investigation.

\section{Funding:}

This paper is derived from a specialty thesis No. 398017 at Isfahan University of Medical Sciences, Isfahan, Iran. The university vice chancellery for research approved the study in 2018 and financially supplied it.

\section{Authors' contributions:}

Fereshteh Mohammadizadeh and Mahsa Bagherian Dehkordi designed the study. Mahsa Bagherian Dehkordi carried out data collection and initial screening of breast cancer samples. Fereshteh Mohammadizadeh and Mahsa Bagherian Dehkordi contributed to the microscopic examination of immunohistochemically stained sections, interpretation of findings, and writing of the final manuscript. Both of them have approved the final manuscript for publication.

\section{Acknowledgements:}

The authors would like to thank Isfahan University of Medical Sciences vice chancellery for research (Isfahan, Iran) for financial support of this study.

\section{References}

1. Kumar V, Abbas AK, Aster JC. Robbins basic pathology e-book: Elsevier Health Sciences; 2017.

2. Smith RA, DeSantis CE. Breast Cancer Epidemiology. Breast Imaging. 2018.

3. Rojas K, Stuckey A. Breast cancer epidemiology and risk factors. Clinical obstetrics and gynecology. 2016;59(4):651-72.

4. Mohammadizadeh F, Mahmudi F. Evaluation of human cytomegalovirus antigen expression in invasive breast carcinoma in a population of Iranian patients. Infectious Agents and Cancer. 2017;12(1):39.

5. Harkins LE, Matlaf LA, Soroceanu L, Klemm K, Britt WJ, Wang W, et al. Detection of human cytomegalovirus in normal and neoplastic breast epithelium. Herpesviridae. 2010;1(1):8.

6. McPherson K, Steel C, Dixon J. ABC of breast diseases: breast cancer-epidemiology, risk factors, and genetics. BMJ: British Medical Journal. 2000;321(7261):624.

7. Somiari SB, Somiari RI, Heckman CM, Olsen CH, Jordan RM, Russell SJ, et al. Circulating MMP2 and MMP9 in breast cancer-potential role in classification of patients into low risk, high risk, benign disease and breast cancer categories. International journal of cancer. 2006;119(6):1403-11. 
8. Duffy MJ, Maguire TM, Hill A, McDermott E, O'Higgins N. Metalloproteinases: role in breast carcinogenesis, invasion and metastasis. Breast cancer research. 2000;2(4):252.

9. Liotta L, Tryggvason K, Garbisa S, Hart I, Foltz C, Shafie S. Metastatic potential correlates with enzymatic degradation of basement membrane collagen. Nature. 1980;284(5751):67-8.

10. Sorsa T, Tjaderhane L, Salo T. Matrix metalloproteinases (MMPs) in oral diseases. Oral diseases. 2004;10(6):311-8.

11. Angahar L. An overview of breast cancer epidemiology, risk factors, pathophysiology, and cancer risks reduction. MOJ Biol Med. 2017;1(4):00019.

12. Tabatabaei-Malazy O, Qorbani M, Samavat T, Sharifı F, Larijani B, Fakhrzadeh H. Prevalence of dyslipidemia in Iran: a systematic review and meta-analysis study. Int J Prev Med. 2014;5(4):373.

13. Pellikainen JM, Ropponen KM, Kataja VV, Kellokoski JK, Eskelinen MJ, Kosma V-M. Expression of matrix metalloproteinase (MMP)-2 and MMP-9 in breast cancer with a special reference to activator protein-2, HER2, and prognosis. Clinical cancer research. 2004;10(22):7621-8.

14. Scorilas A, Karameris A, Arnogiannaki N, Ardavanis A, Bassilopoulos P, Trangas T, et al. Overexpression of matrix-metalloproteinase-9 in human breast cancer: a potential favourable indicator in node-negative patients. British journal of cancer. 2001;84(11):1488-96.

15. Hoikkala S, Pääkkö P, Soini Y, Mäkitaro R, Kinnula V, Turpeenniemi-Hujanen T. Tissue MMP-2/TIMP-2complex are better prognostic factors than serum MMP-2, MMP-9 or TIMP-1 in Stage I-III lung carcinoma. Cancer letters. 2006;236(1):125-32.

16. Zhao Z-S, Zhou J-L, Yao G-Y, Ru G-Q, Ma J, Ruan J. Correlative studies on bFGF mRNA and MMP-9 mRNA expressions with microvascular density, progression, and prognosis of gastric carcinomas. World journal of gastroenterology: WJG. 2005;11(21):3227.

17. Fernandez-Garcia B, Eiró N, Marín L, González-Reyes S, González LO, Lamelas ML, et al. Expression and prognostic significance of fibronectin and matrix metalloproteases in breast cancer metastasis. Histopathology. 2014;64(4):512-22.

18. Shen Z, Zhu D, Liu J, Chen J, Liu Y, Hu C, et al. 27-Hydroxycholesterol induces invasion and migration of breast cancer cells by increasing MMP9 and generating EMT through activation of STAT-3. Environmental toxicology and pharmacology. 2017; 51:1-8.

19. Drzewiecka-Jędrzejczyk M, Wlazeł R, Terlecka M, Jabłoński S. Serum metalloproteinase-2 and tissue inhibitor of metalloproteinase-2 in lung carcinoma patients. Journal of thoracic disease. 2017;9(12):5306.

20. Jinga D, Blidaru A, Condrea I, Ardeleanu C, Dragomir C, Szegli G, et al. MMP-9 and MMP-2 gelatinases and TIMP-1 and TIMP-2 inhibitors in breast cancer: correlations with prognostic factors. Journal of cellular and molecular medicine. 2006;10(2):499-510.

21. Talvensaari-Mattila A, Turpeenniemi-Hujanen T. High preoperative serum TIMP-1 is a prognostic indicator for survival in breast carcinoma. Breast cancer research and treatment. 2005;89(1):29-34.

22. Voorzanger-Rousselot N, Juillet F, Mareau E, Zimmermann J, Kalebic T, Garnero P. Association of 12 serum biochemical markers of angiogenesis, tumour invasion and bone turnover with bone 
metastases from breast cancer: a crossectional and longitudinal evaluation. British journal of cancer. 2006;95(4):506.

23. Hanemaaijer R, Verheijen JH, Maguire TM, Visser H, Toet K, McDermott E, et al. Increased gelatinase$A$ and gelatinase-B activities in malignant vs. benign breast tumors. International journal of cancer. 2000;86(2):204-7.

24. Garbett E, Reed M, Stephenson T, Brown N. Proteolysis in human breast cancer. Molecular Pathology. 2000;53(2):99.

25. Padala C, Tupurani MA, Puranam K, Gantala S, Shyamala N, Kondapalli MS, et al. Synergistic effect of collagenase-1 (MMP1), stromelysin-1 (MMP3) and gelatinase-B (MMP9) gene polymorphisms in breast cancer. PloS one. 2017;12(9):e0184448.

26. Sun XF, Shao YB, Liu MG, Chen Q, Liu ZJ, Xu B, et al. High-concentration glucose enhances invasion in invasive ductal breast carcinoma by promoting Glut1/MMP2/MMP9 axis expression. Oncology letters. 2017;13(5):2989-95.

27. Lou C, Zhu Z, Zhao Y, Zhu R, Zhao H. Arctigenin, a lignan from Arctium lappa L., inhibits metastasis of human breast cancer cells through the downregulation of MMP-2/-9 and heparanase in MDA-MB231 cells. Oncology reports. 2017;37(1):179-84.

28. Reggiani F, Labanca V, Mancuso P, Rabascio C, Talarico G, Orecchioni S, et al. Adipose progenitor cell secretion of GM-CSF and MMP9 promotes a stromal and immunological microenvironment that supports breast cancer progression. Cancer research. 2017;77(18):5169-82.

29. Wu ZS, Wu Q, Yang JH, Wang HQ, Ding XD, Yang F, et al. Prognostic significance of MMP-9 and TIMP-1 serum and tissue expression in breast cancer. International journal of cancer. 2008;122(9):2050-6.

30. Li H-c, Cao D-c, Liu Y, Hou Y-f, Wu J, Lu J-s, et al. Prognostic value of matrix metalloproteinases (MMP-2 and MMP-9) in patients with lymph node-negative breast carcinoma. Breast cancer research and treatment. 2004;88(1):75-85.

31. Mylona E, Nomikos A, Magkou C, Kamberou M, Papassideri I, Keramopoulos A, et al. The clinicopathological and prognostic significance of membrane type 1 matrix metalloproteinase (MT1MMP) and MMP-9 according to their localization in invasive breast carcinoma. Histopathology. 2007;50(3):338-47.

\section{Figures}




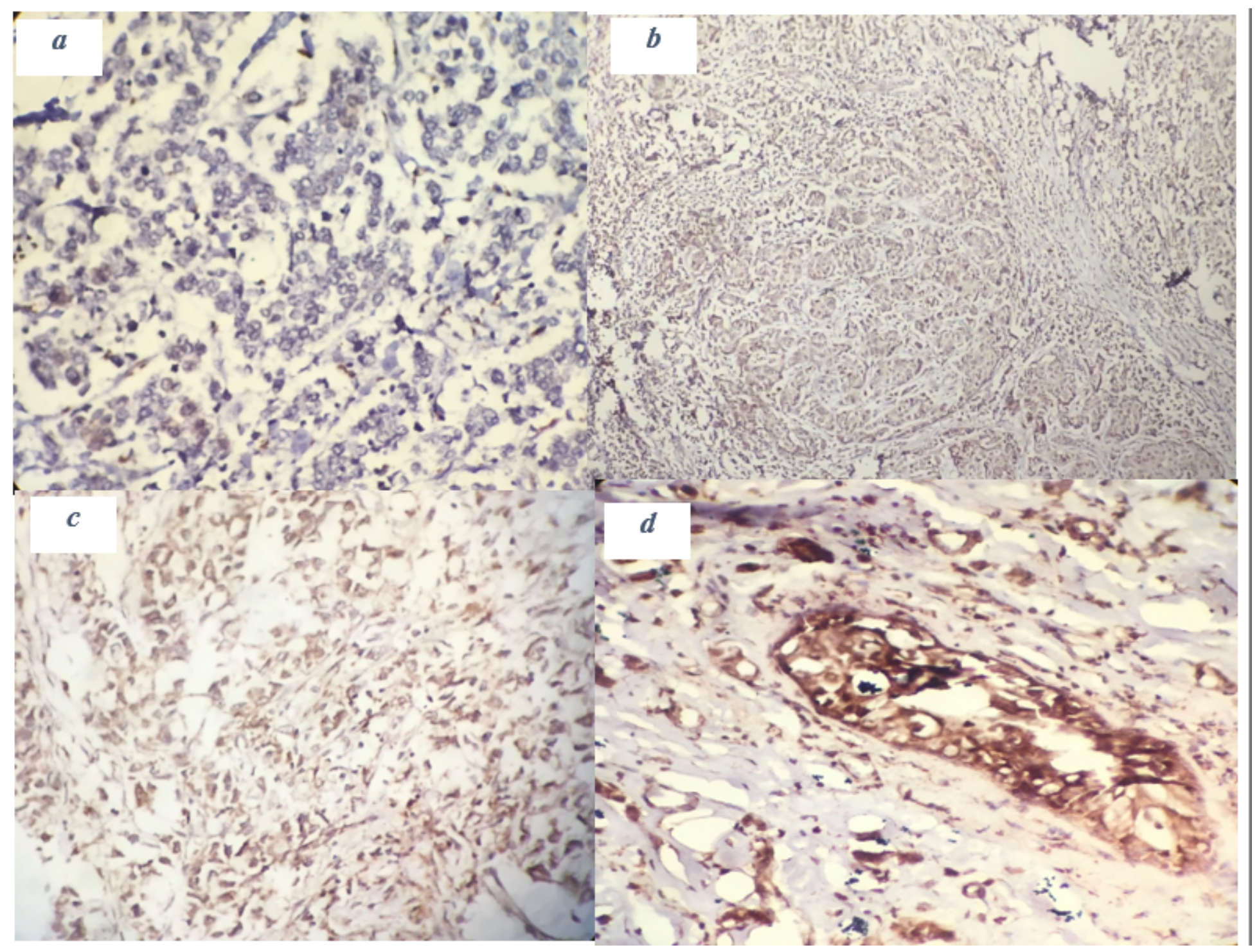

Figure 1

Immunohistochemical staining for evaluation of intraepithelial MMP-9 in breast carcinoma: a- No staining (x40 objective), b- Weak staining (x10 objective), c- Moderate staining (x40 objective), d- Strong staining ( $x 40$ objective). 